\title{
Educação do Campo, CTS, Paulo Freire e Currículo: pesquisas, confluências e aproximações
}

\author{
Rural Education, STS, Paulo Freire and Curriculum: \\ research, confluences and approximations
}

Jair Werlang ${ }^{1}$

Patrícia Barbosa Pereira²

\begin{abstract}
'Universidade Federal do Paraná (UFPR), Setor de Ciências Exatas, Programa de Pós-Graduação em Educação em Ciências e em Matemática, Curitiba,PR, Brasil. Autor correspondente: jairwe70@gmail.com

${ }^{2}$ Universidade Federal do Paraná (UFPR), Setor de Educação, Departamento de Teoria e Prática de Ensino, Curitiba, PR, Brasil.
\end{abstract}

Resumo: Este artigo se constrói pelas leituras sobre Ciência-Tecnologia-Sociedade (CTS) na educação, ideias freireanas, currículo e Educação do Campo. Como principal objetivo, intentamos mostrar confluências e aproximações entre esses temas e suas contribuições às práticas pedagógicas na Educação do Campo. Além dessas leituras, pesquisamos no Portal de Periódicos da Capes, Biblioteca Digital Brasileira de Teses e Dissertações (BDTD) e na Scientific Eletronic Library Online (SciELO), com objetivo de localizar a presença associada dos temas em trabalhos acadêmicos, destacando contextos, sujeitos e especificidades. Percebemos aspectos convergentes entre os temas e potencial de contribuição para uma educação que valorize a crítica, a autonomia e a participação social. Tais resultados apontam ainda que, embora isoladamente, ideias associadas à Educação do Campo, CTS, Paulo Freire e currículo sejam objetos de estudo em muitos trabalhos, conjugadas, entretanto, mesmo com articulações potentes, encontram-se em poucas pesquisas.

Palavras-chave: Educação do campo; CTS; Paulo Freire; Currículo; Pesquisa acadêmica.

Abstract: This article is grounded in the readings on Science - Technology - Society (STS) in education, Freirean ideas, curriculum, and Rural Education. As the main purpose, we intend to show confluences and similarities between these themes and their contributions to pedagogical practices in Rural Education. In addition to these readings, we searched into the Capes Journals Portal, Brazilian Digital Library of Theses and Dissertations (BDTD) and the Online Scientific Electronic Library (SciELO), in order to find the associated presence of themes in academic works, highlighting contexts, subjects and specificities. We noticed converging aspects between the themes and the potential to contribute to an education that values criticism, autonomy and social participation. Such results also point out that, although in isolation, ideas associated with Rural Education, STS, Paulo Freire and curriculum are objects of study in many works, which combined, however, even with powerful articulations, are only found in few studies.

Keywords: Rural education; STS; Paulo Freire; Curriculum; Academic research.

Recebido em: $11 / 07 / 2020$

Aprovado em: 07/12/2020 


\section{Introdução}

Este artigo é o recorte de um trabalho mais amplo desenvolvido durante uma pesquisa realizada em um município localizado na região metropolitana de Curitiba, no Estado do Paraná. Essa pesquisa teve como principal objeto de análise a Educação do Campo dentro de um Campo em transformação, oscilando entre o modo de vida urbano e rural. Porém, tendo em vista a delicada e complexa situação presente nas áreas rurais brasileiras, dadas as histórias de lutas, ocupações e relações de poder que se estabeleceram ao longo do tempo, com influência direta nos modos das pessoas viverem, trabalharem, organizarem-se e, como não poderia deixar de ser, na educação que nesses espaços se desenvolve, optamos por ampliar a discussão, considerando temas que, dadas as características e a importância, poderiam potencializar a própria existência de uma Educação do Campo.

Nesse sentido, com base em leituras de autores com influências progressistas, como Auler (2011), Auler e Delizoicov (2006), Auler, Dalmolin e Fenalti (2009), Caldart (2011), Freire (1996, 2017, 2019), Molina e Nadal (2012), Santos e Auler (2019), Santos e Mortimer (2000), entre outros, miramos, neste trabalho, as aproximações entre Educação do Campo, as ideias freireanas, os pressupostos da Educação com foco nas relações entre Ciência-Tecnologia-Sociedade (CTS) e as discussões sobre currículo, por meio do levantamento de algumas pesquisas da área da Educação e Educação em Ciências.

Quando pensamos na Educação do Campo, temos em perspectiva uma educação para muito além de uma proposta pedagógica. Ela está associada à visão de campo, desenvolvimento e função do meio rural na sociedade brasileira. O objetivo não é, de maneira alguma, fixar as pessoas onde estão, mas:

[...] um dos princípios, é garantir a elas o direito de acesso ao conhecimento sobre o local onde vivem, que garante sua sobrevivência social e material, além dos saberes universais, para que decidam se querem ficar ali ou, caso contrário, tenham condições de viver na cidade. (MOLINA; NADAL, 2012, p. 2).

Além disso, a Educação do Campo é componente do movimento de educação popular, visto que, inobstante a diversidade e as possíveis disputas no campo teórico da área, seus objetivos estão comprometidos com a transformação social (GONÇALVES, 2018 , p. 27). Assim, inerentemente vinculada às realidades e às necessidades do público a qual se destina, tem em vista, justamente, a condição de crítica, compreensão e ação nessas/dessas realidades. Por isso, parece-nos que o legado teórico e epistemológico de Paulo Freire, com seu apreço à crítica, ao diálogo e à parceria entre educador e educandos, é ponto fulcral.

Nesse sentido, para Freire, toda prática escolar está arraigada no contexto manifesto, nas diferentes dimensões da realidade local, em seus sujeitos e processos de construção do real, nas inter-relações entre culturas e saberes, comportamentos e posicionamentos ético-políticos e práticas socioculturais da comunidade (SAUL; SILVA, 2011 , p. 3). Ademais, as influências e as implicações dos desdobramentos envolvendo a Ciência e Tecnologia (CT) na sociedade, com potencial de mudanças cada vez mais latentes na vida das pessoas e nos espaços que ocupam, são vivenciadas, também, no campo. Como exemplos, podemos citar a mecanização em larga escala, bem como a 
utilização de fertilizantes e agrotóxicos, que mudaram profundamente as formas de se produzir e trabalhar.

Porém, as implicações desses fatores não estacionaram apenas no aspecto laboral e de produção, vieram acompanhadas de grandes mudanças nos diversos aspectos da vida. A concentração de terras, a redução drástica da população do campo e, consequentemente, a diminuição das comunidades rurais, foram situações que impactaram significativamente os modos de viver no campo, suas escolas e a educação camponesa.

Por tudo isso, em virtude dessa gama de influências que a ciência e a tecnologia exercem sobre a sociedade, mas também com vistas a compreender como as relações de poder e persuasão de certos grupos podem determinar os rumos e as prioridades dos estudos científicos e tecnológicos, os pressupostos da Educação CTS despontam nesse cenário como importantes e podem se aliar com os esforços da concretização e o fortalecimento da Educação do Campo.

Nesse caminho, parece-nos fundamental uma leitura cuidadosa da realidade, o que, conforme Santos e Auler (2019, p. 490), pode possibilitar a "[...] compreensão crítica das interações entre ciência-tecnologia-sociedade - problematização e superação da suposta neutralidade - aspecto que encontra contribuições no campo CTS", convergindo para que essa condição de compreensão da realidade favoreça, ainda, o envolvimento das pessoas na tomada de decisões no que concerne às suas vidas.

Para Auler, Dalmolin e Fenalti (2009, p. 8), "[...] a busca de participação, de democratização das decisões em temas sociais envolvendo Ciência e Tecnologia", além de ser objetivo do movimento CTS, guarda elementos comuns à matriz teórico-filosófica de Paulo Freire. Entendemos, por extensão e relação, que tal movimento democrático seja, também, um dos pressupostos e objetivos da Educação do Campo.

Embora a presença de temas e estratégias que sejam basilares e favoreçam as ideias em torno da Educação do Campo nos currículos não garanta a efetividade das práticas que a tornem uma realidade, os planos e orientações curriculares podem se apresentar como canais importantes. No entanto, para que isso aconteça, parece fundamental que, primeiramente, haja a intencionalidade por parte de quem atua nas escolas, além de uma necessária abertura de espaço para esses profissionais, e até mesmo à própria comunidade, para que, coletivamente, participem da elaboração de planos e currículos. Por esse viés,

O currículo nunca é apenas um conjunto neutro de conhecimentos, que de algum modo aparece nos textos e nas salas de aula de uma nação. Ele sempre parte de uma tradição seletiva, resultado da seleção de alguém, da visão de algum grupo acerca do que seja conhecimento legítimo. É produto das tensões, conflitos e concessões culturais, políticas e econômicas que organizam e desorganizam um povo. (APPLE, 2013, p 71).

Cientes da potência dessas proximidades e articulações entre Educação do Campo, CTS, perpassando pressupostos freireanos e questões curriculares, tornou-se instigante a ideia de compreendermos como tais temáticas têm aparecido de forma conjunta nos trabalhos e pesquisas desenvolvidas no meio acadêmico do Brasil, mais especificamente na área da Educação e Educação em Ciências. Como um caminho para a leitura de tais aproximações, inicialmente, definimos um panorama sobre os aportes 
teóricos e possíveis convergências entre o movimento da Educação do Campo, a abordagem CTS, as ideias de Paulo Freire para a educação e os currículos.

Depois, com vistas a se traçar um cenário de como esses temas aparecem conjuntamente nas publicações e pesquisas que se desenvolvem no Brasil, serão apresentados os dados de levantamentos realizados no Portal de Periódicos da Capes, na Biblioteca Digital Brasileira de Teses e Dissertações (BDTD) e na Scientific Eletronic Library Online (SciELO).

A seguir, com base nos dados constituídos, será apresentada uma análise voltada à localização das instituições em que os trabalhos foram realizados, os contextos das pesquisas, os sujeitos pesquisados, os objetivos e as temáticas dos estudos. Ademais, foi realizada uma breve incursão em cada um deles, com objetivo de levantar algumas especificidades que aqui serão enunciadas.

\section{Educação do Campo, CTS, Paulo Freire e Currículo: confluências e aproximações}

Ao falarmos de Educação do Campo e currículo, bem como sobre uma educação, ensino e escolas que se aproximem e dialoguem com as pessoas e suas comunidades, cabe pensarmos em ideias e estratégias que podem apoiar e consolidar essa condição.

Nesse sentido, parecem-nos inegáveis as aproximações entre os movimentos da Educação do Campo às abordagens da Educação CTS e às ideias de Paulo Freire. São correntes que, embora com origem em contextos distintos (ROSO et al., 2015), surgem frente à postura questionadora da realidade, apontam para ideias transformadoras, têm objetivos comuns e com potencial de produzirem reflexos na educação, no trabalho de educadores e na vida de educandos.

Um elemento agregador a ser destacado na articulação entre a Educação do Campo e a Educação CTS, é a importância que ambas demonstram ter para com as pessoas, com a realidade e o ambiente em que elas vivem, no sentido de contribuir para a construção de um posicionamento crítico dos sujeitos educandos em relação às condições sociais, econômicas e ambientais nas quais se encontram.

Nesse sentido, o movimento da Educação do Campo se destaca como um exemplo, já que vai além da luta por escolas, pois, em seu cerne, intenciona envolver aspectos mais significativos e abrangentes na educação, como o próprio Campo e a condição de seus habitantes. Em consonância, orienta-se a Educação CTS, a partir da possibilidade de se desenvolver um trabalho conectado com o conjunto da sociedade e de se discutir as implicações da ciência e da tecnologia na vida das pessoas.

Além disso, segundo Santos e Auler (2019), o campo CTS enfrenta o desafio de abordar com mais profundidade o papel dos valores que direcionam o desenvolvimento científico e tecnológico. Essa condição é fundamental para que não se tenha em conta apenas as influências científicas e tecnológicas na vida humana como se fossem algo dado. Para os autores, "[...] o desenvolvimento da CT não tem vida própria, mas impulsionado por interesses e valores, estes, contemplando o conjunto da sociedade, numa educação crítica e transformadora, precisam estar representados nas PCT - Políticas CientíficoTecnológicas" (SANTOS; AULER, 2019, p. 486, grifos nossos).

Portanto, esses dois movimentos caminham no sentido da aproximação entre as pessoas aos contextos em que vivem, tendo na educação um elemento catalizador para 
que essa condição se estabeleça. Por isso, pressupõem também uma aproximação maior entre educador e educando, indo ao encontro do que parece fundamental na perspectiva freireana, o diálogo. Conforme o próprio Freire demarca: "[...] a educação é comunicação, é diálogo, na medida em que não é a transferência de saber, mas um encontro de sujeitos interlocutores [...]" (FREIRE, 2017, p. 89).

Ainda, segundo Freire (2019, p. 116), na perspectiva de um "[...] educadoreducando, dialógico, problematizador, o conteúdo programático da educação não é uma doação ou uma imposição". Para o autor: "[...] é na realidade mediatizadora, na consciência que dela tenhamos, educadores e povo, que iremos buscar o conteúdo programático da educação" (FREIRE, 2019, p. 121).

A Educação CTS, ao lançar um olhar para a ciência não como coisa dada, pronta e imutável, quase um espectro que paira sobre o humano, mas como aquilo que de fato é uma construção humana, por isso, histórica, que carrega em si os sentidos, significados e interesses de quem a desenvolveu, ajuda-nos na compreensão do mundo e da realidade relacional dos sujeitos com esse mundo, o que é ponto central no trabalho de Paulo Freire. Assim, a articulação entre as duas áreas "[...] resulta da compreensão de que a busca de participação, de democratização das decisões em temas sociais envolvendo CT, objetivo do movimento CTS, aproxima-se de postulações freirianas" (AULER, 2011, p. 75).

Por sua vez, o Ensino de Ciências, quando assume essa perspectiva, colocase em uma posição que ultrapassa a simples ideia de um movimento unidirecional de transferência de conhecimentos entre professor e estudante. Em contrapartida, toma como pressuposto o debate, o diálogo e a ideia de construção conjunta entre sujeitos educandos. Dessa forma, terá potencial para contribuir no sentido de que as pessoas compreendam as relações e influências que existem entre ciência, tecnologia e a sociedade, ao favorecer "[...] uma educação, particularmente uma educação em ciências, que contribua para a constituição de valores democráticos e sustentáveis" (AULER, 2011, p. 94).

Mesmo que se concorde com Pinto (1970 apud STRIEDER, 2012, p. 102), para quem "[...] a ideia de estarmos vivendo uma época de esplendor tecnológico é inteiramente ingênua, pois, o mesmo pensaram os homens de todas as fases históricas, precedentes em relação ao seu tempo", as implicações da ciência e da tecnologia, atualmente, geram transformações a uma velocidade talvez antes não experimentada e com inédito potencial de desestabilização social e ambiental.

Para Beck (2011), vivemos em uma "sociedade de risco". No entanto, segundo ele, o progresso parece ser um substituto para questionamentos e se mostra uma espécie de consentimento prévio em relação a metas e resultados, mesmo que não sejam conhecidos e nominados.

Considerando que, diariamente, os professores têm a oportunidade de desenvolverem um potencial trabalho de construção e propagação de conhecimentos, salta aos olhos a importância de se trabalhar, nas escolas, uma educação que esteja atenta aos riscos e necessidades desse momento que o mundo vive. Está nas escolas, no trabalho do professor, na participação dos estudantes e da comunidade, uma possibilidade única de discussão sobre a sociedade e seus rumos.

Hoje é inegável que as transformações da ciência e da tecnologia determinem, em grande parte, os caminhos da sociedade, influenciando vidas, embora não se possa 
negar a influência de certos grupos e seus interesses nos rumos da própria ciência. Portanto, são indissociáveis, nesse aspecto, as influências mútuas entre a ciência e tecnologia na sociedade e desta nos rumos da CT. Assim:

Se há a defesa da participação social no direcionamento dado ao desenvolvimento da $\mathrm{CT}$, está presente a compreensão, mesmo não explicitada, de que a CT não cai do céu pronta, mas recebe o condicionamento da sociedade ou de setores dessa. (SANTOS; AULER, 2019, p. 494).

Por isso, trabalhar com a proposta da Educação CTS é levar em consideração essa condição de tripla implicação. Nesse sentido, para Santos e Mortimer (2000, p. 113): "[...] os trabalhos curriculares em CTS surgiram, assim, como decorrência da necessidade de formar o cidadão em ciência e tecnologia, o que não vinha sendo alcançado adequadamente pelo ensino convencional de ciências."

Esse tipo de proposição visa desnaturalizar um modelo linear, no qual o desenvolvimento científico implica desenvolvimento tecnológico e este em desenvolvimento econômico que, por fim, resultam na ideia ingênua do aumento de bem-estar social (AULER; DELIZOICOV, 2006). Além disso, tal prática possibilita um trabalho a partir de aspectos importantes na vida das pessoas, como o desenvolvimento de valores, participação e autonomia:

Os processos de investigação científica e tecnológica propiciariam a participação ativa dos alunos na obtenção de informações, solução de problemas e tomada de decisão. A interação entre ciência, tecnologia e sociedade propiciaria o desenvolvimento de valores e ideias por meio de estudos de temas locais, políticas públicas e temas globais. (SANTOS; MORTIMER, 2000, p. 115).

A busca pela participação da sociedade por democratizar a tomada de decisões, quando entram em questão temas sociais envolvendo ciência e tecnologia, denota sintonia com os fundamentos teórico-filosóficos postulados por Paulo Freire, que, como pressupostos educacionais, direcionam "[...] para além do simples treinamento de competências e habilidades" (AULER; DELIZOICOV, 2006, p. 340-341).

Essas características, quando presentes nos currículos, podem construir importante ponto de apoio para que se consiga fazer da educação um movimento de imersão das pessoas no mundo e nas suas relações. Para Pernambuco (2014, p. 8), "[...] aqui, apresenta-se uma possibilidade de articular o ensino com o aprendizado, como forma de construção de um conhecimento socialmente relevante". Assim, o resultado da construção desse conhecimento é a possibilidade da transformação da realidade e a conquista de uma condição de vida melhor para as pessoas.

A história de formação do movimento CTS, o contexto e o momento histórico em que aconteceu, diante de problemas sociais e ambientais que se agravavam, apontam a um novo olhar à própria ciência e à tecnologia e/nas suas relações com a sociedade:

Originários dos finais dos anos 1960 e princípios dos anos 1970, os estudos CTS, ou estudos sociais da ciência e da tecnologia, refletem no âmbito acadêmico e educativo essa nova percepção da ciência e da tecnologia e de suas relações com a sociedade. (BAZZO et al., 2003, p. 125). 
A partir da crítica do que se tem e da necessidade de transformação, a inspiração vira prática e se concretiza, porém, sem que, segundo Strieder (2012, p. 136), tenha uma direção única ou pré-determinada, dada a complexidade e as várias formas de se olhar para a ciência, a tecnologia e a sociedade. Desse modo, como não há unanimidade de olhares para esses três temas, ciência, tecnologia e sociedade, mesmo que tratados separadamente: "[...] fica praticamente impossível pensar que possa haver uma compreensão única sobre como se dá a(s) relação(ões) CTS e, além disso, de como trabalhar tais questões de um ponto de vista educacional" (STRIEDER, 2012, p. 137).

Assim como a perspectiva CTS, a Educação do Campo emerge da crítica a uma realidade social e da necessidade de construção de uma condição de vida diferente. Uma luta que, embora requeira apoio de agentes externos, nasce e se desenvolve pela atuação dos próprios sujeitos afetados, cresce na e pela força dos movimentos, dos coletivos, o que, para Gonçalves (2018, p. 25), "[...] tem como pressuposto a necessidade de construir novos sentidos para esse espaço, como um espaço de formação universal dos sujeitos".

Nesse sentido, sua concretização e seu fortalecimento irradiam para o conjunto da sociedade, afinal, não se pode falar apenas em Educação do Campo no interior dos Movimentos Sociais, mas para todos os sujeitos do Campo. É autêntico também que, ao se falar em Educação do Campo, fala-se em educação popular, portanto, implicamse interesses e expectativas comuns aos demais trabalhadores è sociedade como um todo, seja no Campo ou na cidade.

Essa perspectiva permite que discutamos (a partir e com foco nas) características e demandas da Educação do Campo, mesmo nos contextos de Campo em transformação, alternando-se por vezes, a depender da situação, entre a condição de Campo e cidade, nas periferias, nos territórios periurbanos e, por que não, no contexto urbano propriamente dito. Podemos ir adiante, pois o que o Movimento da Educação do Campo pressupõe e objetiva não fixa fronteiras entre contextos ou grupos sociais.

Além das aproximações que podem ser estabelecidas entre Educação do Campo e CTS, o Ensino de Ciências guarda com o Campo uma relação muito forte, afinal, como não levar em consideração os conhecimentos científicos e tecnológicos ao se falar, por exemplo, na produção de alimentos, no uso da terra e na preservação ambiental? Santos e Mortimer (2000, p. 120) elencam uma série de temas que, no contexto brasileiro, poderiam ser objeto de discussão, como: exploração mineral, ocupação humana e poluição ambiental (êxodo populacional, questão agrária), manejo do lixo, controle e risco de produtos químicos, produção de alimentos (distribuição, transgênicos), agroindústria e suas implicações (monocultura, impactos ambientais), desenvolvimento da indústria brasileira (dependência tecnológica), fontes de energia e seus efeitos, preservação ambiental.

Trazemos aqui a fala de uma professora de uma escola do Campo, com quem conversamos na pesquisa que citamos na introdução. Seu discurso parece apontar para esse sentido de proximidade entre as condições de vida no Campo e o Ensino de Ciências, em que "trabalhar Ciências aqui ou trabalhar Ciências em outro lugar, é que aqui eu tenho acesso à natureza, por exemplo, para trabalhar. Então é o mesmo currículo só que um trabalho diferente do que eu conseguiria fazer em outros lugares." 
Estão aí, quem sabe, os mais latentes exemplos da importância de se considerar as relações CTS no ensino e de como o Campo brasileiro, com toda a sua dimensão e variedade de características, bem como sua população, são diretamente afetados por vários desses eventos que não se limitam ao Campo, mas implicam e geram influência em todos os espaços, sejam urbanos ou rurais.

Parece fundamental, então, em uma escola localizada no Campo, um direcionamento curricular e uma prática pedagógica que tenham como perspectiva trabalhar nas aulas de ciências, mas não só nessas, as implicações do desenvolvimento científico e tecnológico na vida das pessoas, nas transformações do trabalho, na forma de se alimentarem e de produzirem. Um trabalho que coloque em pauta os riscos e benefícios dos avanços científicos e tecnológicos, que não devem ser camuflados, mas cada vez mais problematizados.

Nesse sentido, tanto o enfoque educacional CTS, quanto os princípios e métodos freireanos para a educação, podem contribuir de forma muito significativa. Auler e Bazzo (2001, p. 3), ao falarem dos objetivos do enfoque CTS no Ensino de Ciências, afirmam que este pode "[...] promover o interesse dos estudantes em relacionar a ciência com as aplicações tecnológicas e os fenômenos da vida cotidiana e abordar o estudo daqueles fatos e aplicações científicas que tenham uma maior relevância social".

Da mesma forma, a investigação temática proposta por Paulo Freire tem em perspectiva, no processo educativo, considerar a vida dos sujeitos educandos, problematizando e criticando as condições em que se encontram, para poderem refletir e pensar em maneiras de agir. "Um esforço comum de consciência da realidade e de autoconsciência" (FREIRE, 2019, p. 138).

Auler (2007), como forma de sintetizar a aproximação Freire-CTS, esquematiza essa condição fazendo uma correspondência entre a leitura crítica da realidade em Freire, com a compreensão crítica sobre as interações CTS, no campo CTS. Assim, essa crítica da realidade potencializa no referencial freireano a superação da 'cultura do silêncio': ser humano - sujeito e não objeto histórico -, sendo que, por sua vez, a crítica às interações CTS pode levar à superação do modelo de decisões tecnocráticas: democratização das decisões em temas envolvendo CT.

A condição de pensar a partir do local em que se vive, buscar a partir dele - dos seus problemas, suas necessidades, da vida de fato - subsídios para que se desenvolva o processo educativo, caminha no sentido de dar significado, da postura crítica e da busca de autonomia. Para Freire: "[...] deste modo, a análise crítica de uma dimensão significativo-existencial possibilita aos indivíduos uma nova postura, também crítica, em face das 'situações-limite'" (FREIRE, 2019, p. 134).

Para o autor, as situações-limite "[...] não devem ser tomadas como se fossem barreiras insuperáveis, mais além das quais nada existisse" (FREIRE, 2019, p. 125). Além disso, Freire (2019) destaca a análise do professor Paulo Vieira Pinto a respeito das situações-limite, para quem elas "[...] não são o contorno infranqueável onde terminam todas as possibilidades, mas a margem real onde começam as mais ricas possibilidades" (PINTO, 1960, p. 284, grifos nossos).

Assim se constitui e projeta-se a Educação do Campo, nunca somente uma educação para o Campo, que, se o fosse, abdicaria da necessidade da participação ativa e da construção conjunta de educadores e educandos, deixando de lado, inclusive, a 
colaboração da comunidade, o diálogo, para ser, quem sabe, uma extensão, no sentido da simples "transmissão, entrega ou doação" (FREIRE, 2017, p. 20).

Por outro lado, para que se pense uma educação dialógica e comunicativa, há de se analisar os sujeitos envolvidos, neste caso, educadores, educandos, comunidade e o contexto em que vivem, ou seja, onde o trabalho educativo ocorre, efetivamente. Necessário pensar nas relações, na dinâmica que o local tem e das pessoas com ele. Mais ainda, é necessária postura crítica e de questionamento com relação à realidade ambiental, social e existencial. Essa condição de se voltar à realidade, criticar, pensar e construir o que é necessário, só é possível na autonomia.

A autonomia é um objetivo presente tanto na Educação do Campo, na Educação CTS e nas ideias freireanas, um eixo de convergência entre essas propostas. Para Freire (1996, p. 38), o educador tem a tarefa de, na prática, compreender e "[...] desafiar o educando com quem se comunica e a quem comunica, a produzir sua compreensão do que vem sendo comunicado." Sendo possível ao educando compreender e apreender o que se trabalha no processo da comunicação educativa, poderá ter argumentos para analisar e compreender a realidade em que vive.

Esse aspecto, na Educação do Campo, significa um sentido amplo de educação, como, segundo Caldart (2011, p. 116, grifos nossos), "[...] um processo de formação humana, que constrói referências culturais e políticas para a intervenção das pessoas e dos sujeitos sociais na realidade".

Também na perspectiva da educação CTS, conforme Santos e Mortimer (2000), destaca-se, entre os objetivos, o desenvolvimento de valores. Valores que, fundamentados em interesses coletivos, na solidariedade e no respeito, na opinião dos autores, são primordiais à formação crítica e à capacidade de escolha das pessoas, diante de situações e produtos que podem pôr em risco a saúde e as condições de equilíbrio ambiental.

Como observamos, ao se falar de educação e autonomia, mira-se a uma perspectiva de formação mais ampla das pessoas, para além do ensino e da técnica. Trabalhar no sentido do coletivo, da capacidade de reflexão e de participação, é um desafio importante e necessário.

Assim, tanto na perspectiva da Educação do Campo, quanto na educação com enfoque CTS, os movimentos não se limitam em si mesmos, em um trabalho ou esforço de melhorar ou aprimorar aquilo que está restrito aos contextos mais próximos, pois o olhar que se dá é para as contradições e as implicações no conjunto da sociedade, bem como na sua transformação. Contribuir para que professores e estudantes discutam esses aspectos e se fortaleçam com argumentos e posturas fundamentadas no conhecimento histórico, filosófico, social, técnico e científico, mostra-se peça chave.

Por isso, a atividade do professor e o processo de ensino-aprendizagem ganham uma maior amplitude, já que os educandos, não se constituem sujeitos a serem simplesmente treinados ou capacitados, mas que possam ampliar conhecimentos e possibilidades de intervirem na dinâmica de suas comunidades.

Nessa linha de pensamento, novamente, as escolhas feitas com relação às questões curriculares são fundamentais, afinal este é um "[...] campo não neutro, mas marcado por intencionalidades, por disputas entre concepções educacionais e entre concepções de sociedade" (ROSO et al., 2015, p. 374, grifo nosso). Conhecer as correntes teóricas em que o currículo se ampara, quais perspectivas de sociedade e 
cidadania trazem em suas propostas, parece-nos decisivo para que seja instrumento de colaboração e de uma prática pedagógica concatenada ao contexto das escolas.

Mas será que, na realidade do Campo, elementos como a Educação do Campo, as propostas da Educação CTS e as ideias de Paulo Freire estão presentes nas escolas e no discurso dos professores? A existência de um debate corrente sobre os temas poderia significar, diante da participação efetiva desses sujeitos nas elaborações e reformulações curriculares, a oportunidade ímpar de um esforço para a presença dessas ideias e perspectivas nos planos e projetos.

Além disso, a autonomia que se pretende para os educandos e o foco dos temas trabalhados podem significar um esforço pela conquista de uma autonomia curricular às escolas e à ampliação das possibilidades de um engajamento efetivo aos contextos locais, às comunidades.

Nesse sentido, as pesquisas e publicações envolvendo esses temas são de grande significância, pois podem fomentar discussões a seu respeito nos cursos de formação de professores, nas escolas e nas comunidades envolvidas. A aproximação com a realidade vivida nas escolas e nos grupos sociais em que os trabalhos de pesquisa se realizam possibilita que as demandas e experiências sejam compartilhadas com os pares e demais setores da sociedade, fortalecendo, assim, a possibilidade de que se estabeleçam ações com foco na educação e demais políticas públicas necessárias.

Porém, como será que Educação do Campo, CTS, Paulo Freire e currículo têm aparecido de forma conjunta nos trabalhos e pesquisas desenvolvidos nos meios acadêmicos do Brasil? Foi na tentativa de se ter um panorama dessa situação que elaboramos a seção a seguir, trazendo uma breve pesquisa em publicações e eventos da área.

\section{A Presença Conjunta em Publicações e Pesquisas no Brasil}

Inicialmente, realizamos pesquisa de forma simples e isolada, para os termos Educação do Campo, currículo, CTS e Paulo Freire, no Portal de Periódicos da Capes, na Biblioteca Digital Brasileira de Teses e Dissertações (BDTD) e na Scientific Eletronic Library Online (SciELO), que retornou um grande número de resultados, conforme indicado na Tabela 1.

Tabela 1 - Resultados pesquisas: Educação do Campo, currículo, CTS e Paulo Freire

\begin{tabular}{lcccc}
\hline \multicolumn{1}{c}{ Descritor } & Portal Periódicos Capes & BDTD & SciELO & Total \\
\hline Educação do Campo & 268 & 844 & 61 & $\mathbf{1 . 1 7 3}$ \\
Currículo & 5.846 & 13.518 & 2.722 & $\mathbf{2 2 . 0 8 6}$ \\
CTS & 936 & 506 & 396 & $\mathbf{1 . 8 3 8}$ \\
Paulo Freire & 1.379 & 1.939 & 387 & $\mathbf{3 . 7 0 5}$ \\
\hline Total & $\mathbf{8 . 4 2 9}$ & $\mathbf{1 6 . 8 0 7}$ & $\mathbf{3 . 5 6 6}$ & $\mathbf{2 8 . 8 0 2}$ \\
\hline
\end{tabular}

Fonte: elaborado pelos autores.

Em função da grande quantidade de resultados, quando os termos foram citados individualmente, e como o objetivo não era analisar isoladamente, mas como se relacionavam nas pesquisas os descritores escolhidos, realizamos buscas conjugadas. Para aperfeiçoar a busca e obter um resultado mais assertivo, procuramos termos exatos, utilizando-se a escrita de cada um deles entre aspas, conforme segue. 
Tabela 2 - Busca conjugada de descritores

\begin{tabular}{lcccc}
\hline Descritor & Portal Periódicos Capes & BDTD & SciELO & Total \\
\hline Educação do Campo / Currículo & 82 & 198 & 7 & $\mathbf{2 8 7}$ \\
Escola do Campo / Currículo & 26 & 124 & 4 & $\mathbf{1 5 4}$ \\
Educação do Campo / CTS & - & 2 & - & $\mathbf{2}$ \\
Escolas do Campo / CTS & - & - & - & - \\
Educação do Campo / Paulo Freire & 27 & 45 & 1 & 73 \\
Escolas do Campo / Paulo Freire & 9 & 13 & - & $\mathbf{2 2}$ \\
\hline Total & $\mathbf{1 4 4}$ & $\mathbf{3 8 2}$ & $\mathbf{1 2}$ & $\mathbf{5 3 8}$ \\
\hline
\end{tabular}

Fonte: elaborado pelos autores.

Ainda assim, tivemos retorno de muitos resultados e, para podermos aproximar mais significativamente os trabalhos a serem selecionados, das discussões realizadas na nossa investigação, optamos por associar três termos: Educação do Campo / currículo / Paulo Freire e Educação do Campo / Currículo / CTS. Os resultados do filtro estão listados na Tabela 3.

Tabela 3 - Busca conjugada de descritores

\begin{tabular}{lcccc}
\hline Descritor & Portal Periódicos Capes & BDTD & ScieLO & Total \\
\hline Educação do Campo / Currículo / CTS & - & 2 & - & $\mathbf{2}$ \\
Educação do Campo / Currículo / Paulo Freire & 15 & 11 & 1 & $\mathbf{2 7}$ \\
\hline Total & $\mathbf{1 5}$ & $\mathbf{1 3}$ & $\mathbf{1}$ & $\mathbf{2 9}$ \\
\hline
\end{tabular}

Fonte: elaborado pelos autores.

A seleção dos trabalhos foi feita com a busca dos descritores em qualquer parte dos textos, resultando, depois de eliminadas as repetições, em 29 trabalhos.

Para ter um panorama dos 29 trabalhos localizados na busca conjugada dos termos Educação do Campo / Currículo / CTS e Educação do Campo / Currículo / Paulo Freire (Tabela 3), fizemos a leitura dos resumos e buscamos saber: (i) a região do Brasil em que se localizavam as instituições dos pesquisadores; (ii) o contexto em que aconteceu o estudo (se no Campo, em que Campo, na Universidade); (iii) os sujeitos envolvidos na pesquisa e (iv) o objeto/temática da investigação, informações organizadas no Quadro 1.

Com relação à localização das instituições (i), observamos um predomínio da região Nordeste, responsável por 12 dos trabalhos selecionados, seguida do Sudeste, com sete pesquisas, Sul, com quatro trabalhos, Centro Oeste e Norte, com três cada uma.

Ao analisarmos os contextos em que ocorreram as investigações (ii), separamos quatro agrupamentos diferentes. Do total, $17^{1}$ pesquisas foram desenvolvidas no Campo, sendo seis no contexto de assentamentos, uma em comunidade quilombola e 11 em outras comunidades rurais. Os demais estudos - 12 pesquisas - tiveram universidades como contexto, na forma de pesquisas documentais e bibliográficas ou envolvendo estudantes das instituições em que se desenvolveram.

\footnotetext{
${ }^{1}$ Ao todo foram 18 locais para 17 pesquisas, pois uma das pesquisas envolveu tanto um assentamento da reforma agrária,quanto uma comunidade quilombola.
} 
As pesquisas tiveram como foco diversos sujeitos e instituições (iii). Duas envolveram estudantes e outras nove envolveram professores da Educação Básica. Duas focaram licenciandos de cursos universitários e quatro estudos tiveram como sujeitos da investigação pessoas residentes de comunidades rurais. Uma das pesquisas teve como foco secretarias de educação de uma região do Estado do Paraná e 11 estudos não estabeleceram sujeitos ou instituições diretamente envolvidas, ocupando-se apenas de estudos bibliográficos e documentais.

Por fim, a análise nos fez definir cinco objetos/temas (iv) centrais nas pesquisas. A maioria delas, 12 investigações, estudaram as implicações e relações entre a educação e a sociedade, que definimos como estudos que envolveram Educação e Sociedade. Essas 12 pesquisas se concentraram na própria Educação do Campo, Educação CTS ou na temática educacional de modo mais geral.

Localizamos ainda seis estudos que trataram da formação de professores, cinco que pesquisaram práticas pedagógicas, três que investigaram programas educacionais, voltados para Educação do Campo e o trabalho com jovens e adultos. Por fim, três pesquisas que cuidaram do tema currículo.

O Quadro 1 sintetiza os dados anteriormente descritos e estabelece um resumo dos 29 trabalhos selecionados.

Quadro 1- Quantidades por região, contexto, sujeitos / instituições e objeto / temática das pesquisas

\begin{tabular}{|c|c|}
\hline Categoria & Quantidade de Pesquisas \\
\hline \multicolumn{2}{|l|}{ 1. Região (i) } \\
\hline 1.1 Centro-Oeste & 3 \\
\hline 1.2 Nordeste & 12 \\
\hline 1.3 Norte & 3 \\
\hline 1.4 Sudeste & 7 \\
\hline $1.5 \mathrm{Sul}$ & 4 \\
\hline \multicolumn{2}{|l|}{ 2. Contexto (ii) } \\
\hline 2.2 Assentamentos & 6 \\
\hline 2.3 Comunidade quilombola & 1 \\
\hline 2.4 Comunidades rurais & 11 \\
\hline 2.5 Universidades & 12 \\
\hline \multicolumn{2}{|l|}{ 3. Sujeito / Instituições (iii) } \\
\hline 3.1 Estudantes da Educação Básica & 2 \\
\hline 3.2 Professores da Educação Básica & 9 \\
\hline 3.3 Licenciandos / Graduandos & 2 \\
\hline 3.4 Escolas da Educação Básica & 2 \\
\hline 3.5 Comunidades do Campo & 4 \\
\hline 3.6 Secretarias de Educação & 1 \\
\hline 3.7 Pesquisa bibliográfica/documental & 11 \\
\hline \multicolumn{2}{|l|}{ 4. Objeto / Temática da pesquisa (iv) } \\
\hline 4.1 Formação de professores & 6 \\
\hline 4.2 Práticas pedagógicas & 5 \\
\hline 4.3 Programas educacionais & 3 \\
\hline 4.4 Educação e Sociedade & 12 \\
\hline 4.5 Currículo & 3 \\
\hline
\end{tabular}

Fonte: elaborado pelos autores. 
Pelos dados apresentados, vemos que as pesquisas envolvendo Educação do Campo ocorrem em todas as regiões do Brasil, em diferentes contextos, com públicos e temáticas variadas. Tiveram relação e discutiram a educação, as formas de vida, de se relacionar das pessoas e em diversas regiões, mostrando a abrangência e importância dos pressupostos e objetivos da Educação do Campo, que vão muito além das necessidades e expectativas das comunidades em que o Movimento surgiu e ganhou força. Não se pode falar em Educação do Campo sem ter em perspectiva o conjunto da sociedade e a educação que nela se faz.

Porém, destacamos que, embora tenha ocorrido limitação pelo recorte e filtros das buscas realizadas, a análise mostrou que nenhuma das pesquisas teve como local de investigação o Campo localizado em regiões próximas de grandes cidades, municípios de regiões metropolitanas ou periurbanas. Todas as pesquisas que envolveram o contexto e os sujeitos da área rural ocorreram em regiões distantes dos grandes centros urbanos.

Esse é um fato importante, uma vez que grande parte da população que habita a área rural se concentra em municípios localizados próximos a grandes centros urbanos. Esses locais, suas populações e suas escolas, por vezes, são ignoradas enquanto pertencentes ao campo, ficando suas especificidades e particularidades perdidas e sem serem consideradas. O debate sobre a Educação do Campo e a presença de seus pressupostos no imaginário dos professores pode representar uma grande oportunidade para que as pessoas que habitam esses locais e a educação que ali se desenvolve considerem as necessidades e expectativas que emergem daquela realidade.

Na próxima seção, discutiremos os aspectos mais relevantes dos trabalhos que mais se aproximavam da nossa busca, ou seja, o trato articulado entre Educação do Campo, CTS, Paulo Freie e Currículo, destacando objetivos, temas, contextos e resultados.

\section{As Especificidades das Pesquisas}

A partir do resultado alcançado, realizamos a leitura dos resumos de todos os 29 trabalhos com a intenção de localizar e selecionar os que pudessem ter uma relação mais direta com o objeto, os objetivos e o contexto da nossa pesquisa, ou seja, que discutissem conjuntamente os temas Educação do Campo, CTS, Paulo Freire e currículo. Assim, identificamos sete produções, entre artigos e dissertações, listados no quadro a seguir, em ordem crescente do ano de publicação, contendo autoria, categoria de trabalho e título. 
Quadro 2- Trabalhos selecionados para análise

\begin{tabular}{|c|c|c|}
\hline Autor (ano) & Categoria & Título \\
\hline Silva (2012) & Dissertação & $\begin{array}{l}\text { Saberes e perspectivas dos docentes em torno do currículo de uma escola pública } \\
\text { rural do RN }\end{array}$ \\
\hline Pimentel (2014) & Dissertação & $\begin{array}{l}\text { Qualidade de ensino - aprendizagem nas salas multisseriadas na Educação do } \\
\text { Campo Capixaba }\end{array}$ \\
\hline Silva (2014) & Dissertação & Conceitos de Ciências para Educação do Campo a partir do tema agriculturas \\
\hline Silva Filho (2014) & Dissertação & $\begin{array}{l}\text { Educação do Campo e Pedagogia Paulo Freire na atualidade: um olhar sobre o } \\
\text { currículo do curso Pedagogia da Terra da UFRN }\end{array}$ \\
\hline Marques (2016) & Dissertação & $\begin{array}{l}\text { Educação Ciência-Tecnologia-Sociedade (CTS): elementos em produções científicas } \\
\text { na Fundação Oswaldo Cruz - Fiocruz }\end{array}$ \\
\hline $\begin{array}{l}\text { Santos e Ferreira } \\
(2018)\end{array}$ & Artigo & $\begin{array}{l}\text { Currículo e Educação do Campo: entre as lutas por uma formação humana crítica } \\
\text { e as proposições pós-críticas do educar }\end{array}$ \\
\hline $\begin{array}{l}\text { Costa e Batista } \\
\text { (2019) }\end{array}$ & Artigo & $\begin{array}{l}\text { Formação continuada de educadores: uma contribuição ao currículo das escolas } \\
\text { do campo }\end{array}$ \\
\hline
\end{tabular}

Fonte: elaborado pelos autores.

Silva (2012) se propôs a analisar os saberes e as perspectivas sobre currículo de professores dos anos iniciais do Ensino Fundamental, considerando, principalmente, os debates sobre Educação do Campo, a partir de autores como Souza, Arroyo, Caldart, Molina e Fernandes. Amparou-se também em Freire, Tardif, Giroux, Moreira, Candau, entre outros autores, para debater os saberes docentes e currículo.

O estudo destaca o papel relevante do professor na construção dos saberes sobre o Campo, suas escolas e a função social delas. Aponta, ainda, para a necessidade de uma formação conceitual específica dos docentes que atuam no Campo, com base na perspectiva histórico-cultural do espaço rural. Afirma a importância do processo de formação permanente dos professores, considerando as especificidades do Campo e da Educação do Campo.

Por sua vez, Pimentel (2014) tomou como foco de investigação as escolas multisseriadas do Campo do Estado do Espírito Santo que, segundo a a utora, apresentam particularidades diversas, já que estão localizadas em comunidades das mais variadas - quilombolas, pescadores, ribeirinhos, indígenas, pequenos agricultores e grandes latifúndios -, porém, sem variação na elaboração de currículos e metodologias de ensino.

Conforme a pesquisadora, os dados levantados permitem concluir que a especificidade de um currículo, pensado para a realidade das comunidades do Campo, aliada às práticas de ensino que favoreçam a participação dos alunos, e considerem seus conhecimentos prévios, favorecem uma aprendizagem significativa e a condição dos educandos como protagonistas do processo.

O estudo de Silva (2014) considerou a produção de conceitos de Ciências para a Educação do Campo, sob o enfoque CTS, utilizando o tema agriculturas. Trabalhou a avaliação, dessa mesma proposta, pelo olhar de professores de Ciências Naturais. Em seu trabalho, buscou as aproximações e as articulações entre as ideias de Paulo Freire e os pressupostos CTS, evidenciando suas contribuições ao Ensino de Ciências e da Educação do Campo. 
As aproximações entre o Movimento por Uma Educação do Campo e a Pedagogia Paulo Freire, a partir de um olhar para o currículo do curso de Pedagogia da Terra, da Universidade Federal do Rio Grande do Norte, foi o estudo desenvolvido por Silva Filho (2014). Utilizando a revisão bibliográfica e a análise documental, a pesquisa buscou conhecer a estrutura curricular do curso, a presença dos princípios da pedagogia freireana nela e a contribuição desta ao debate sobre Educação do Campo.

Segundo as conclusões do autor, o pensamento de Paulo Freire influencia de maneira muito forte o currículo analisado, assim como as ideias freireanas se entrelaçam aos princípios da Educação do Campo, objetivando uma educação dialógica e em favor da luta dos povos oprimidos.

Marques (2016) fez um estudo sobre artigos produzidos por pesquisadores da Fundação Osvaldo Cruz (FIOCRUZ) a partir de 1994, que tivessem como campo específico a política pública de saúde e mantivessem vínculo com educação, Ensino de Ciência e Tecnologia, Ciência-Tecnologia-Sociedade, Tecnologia Social, Educação Popular. Por fim, deveriam manter diálogo com território e sujeitos e atores/atrizes sociais.

A partir de temas da Educação CTS e dos Estudos CTS, como o grau de inserção no território, a representação social dos sujeitos e as inovações metodológicas e métodos, a pesquisa procurou identificar nos artigos as propostas de mudanças sociais e como situaram as Instituições de Ciência e Tecnologia com relação às demandas e aos saberes dos territórios. Revelou-se, segundo a autora, que houve a preocupação de se construir novas metodologias ao trabalho da Educação CTS, valorizando o respeito e a troca de experiência entre pesquisadores e alunos/professores.

O artigo de Santos e Ferreira (2018) toma como referência os cadernos sobre educação do Campo, editados pelo Movimento por uma Educação do Campo e a Proposta curricular para as escolas do campo no território do Velho Chico, elaborados por educadores, instituições governamentais e não governamentais, em região do semiárido baiano. O objetivo foi analisar a relação entre a perspectiva de formação humana, existente nas referidas propostas e as perspectivas pedagógicas pós-críticas/ pós-modernas, nas proposições sobre currículo para as escolas do Campo.

Dessa forma, ressaltam o papel das lutas sociais na construção de uma educação específica aos trabalhadores rurais, cuja resposta institucional foi a formulação e a divulgação de políticas públicas às chamadas minorias: camponeses, povos indígenas e quilombolas.

Costa e Batista (2019) realizaram estudo com objetivo de analisar as contribuições aos currículos de duas escolas de Educação Infantil e Ensino Fundamental localizadas em assentamentos da reforma agrária, no Estado da Paraíba, a partir da formação continuada de professores, tendo como perspectiva os preceitos da Educação do Campo. As formações foram realizadas durante cinco anos e contaram com a orientação de professores e alunos da Universidade Federal da Paraíba.

Como resultado, os autores apontam para a importância da inserção dos temas relacionados à realidade dos sujeitos escolares nos currículos das escolas que, na opinião deles, contribuem para o fortalecimento de um Projeto Político Pedagógico, alinhado aos princípios pedagógicos da Educação do Campo. 
As buscas realizadas no banco de dados Portal de Periódicos da Capes, na Biblioteca Digital Brasileira de Teses e Dissertações (BDTD) e na SciELO mostraram que ainda há um longo caminho a percorrer nas pesquisas quando o objetivo é associar Educação do Campo, Currículo, CTS e Paulo Freire.

Porém, a análise dos estudos permite dizer que as ideias freireanas à educação e à sociedade fazem parte do universo da Educação do Campo, guardando com ela uma profunda aproximação, pois partilham de preceitos e objetivos. Em contrapartida, embora haja uma presença menor de pesquisas que discutam, conjuntamente, Educação do Campo e Educação CTS, não significa que essas duas frentes não se aproximem.

Ao objetivarem uma educação que se volte para o sujeito, sua autonomia, capacidade de decisão e participação, tais campos se identificam. Assim, tanto os pressupostos CTS como as ideias de Paulo Freire podem ser de grande contribuição para que a Educação do Campo conquiste espaço e se fortaleça. Além disso, essa aproximação pode contribuir para que esses temas estejam presentes nos debates e nas construções curriculares.

\section{Considerações Finais}

As leituras permitiram o estabelecimento de confluências entre os temas Educação do Campo, Paulo Freire, Educação CTS e, assim, favorecem a ideia de que a educação é aliada importante dos sujeitos na busca de compreenderem, decidirem e agirem sobre a realidade em que vivem. É possível também dizer que os currículos, vistos não como simples relações de enunciados e conteúdos, mas como objetos concatenadores de interesses e visões de mundo, podem servir para que esses temas sejam emergentes nas escolas, nos discursos de professores que, por fim, poderão culminar como intencionalidades e ações nas práticas pedagógicas. Vale destacar a importância da luta por uma autonomia curricular nas escolas, que poderá aproximar cada vez mais o trabalho que realizam com a vida dos educandos e suas comunidades, o que, por sinal, vai ao encontro das perspectivas da Educação do Campo, CTS e as ideias freireanas.

Embora isso possa ir na contramão do que se estabelece atualmente na educação brasileira, em que emergem as bases curriculares comuns para uma imensa e complexa diversidade, ainda nos cercamos da convicção de que esse esforço, em caminhar com vistas ao diálogo, mas, também, à autonomia, é algo caro e potente para se pensar as diferentes realidades.

A análise dos trabalhos acadêmicos reforça a importância que os temas convergentes sejam postos lado a lado, pois, dessa forma, as especificidades de cada um são reforçadas e complementadas com as características e os objetivos comuns. A pesquisa mostrou serem poucos os artigos, dissertações e teses que articulam os quatro temas aqui discutidos e, quando aparecem de forma conjunta, parte deles serve de cenário ou acessório e não como cerne para debates e reflexões. 
Notamos a presença marcante das ideias de Paulo Freire nos trabalhos que discutem a Educação do Campo, sendo que os pressupostos freireanos para a educação, como a busca de autonomia, da participação, e da crítica, vão ao encontro dos ideais da Educação do Campo. No entanto, cabe destacar que a pura referência às ideias de Freire nas pesquisas não é garantia de que, no desenvolvimento desses trabalhos, os sujeitos envolvidos - professores, estudantes ou a comunidade - tiveram asseguradas duas questões fundamentais sob o ponto de vista freireano, e primordiais, também, na Educação do Campo: a possibilidade da crítica e a liberdade de ação.

Nesse sentido, Brayner (2017) alerta para aquilo de chamou de "Paulofreireanismo", considerando aspectos como o culto à personalidade, à fidelidade doutrinária e à institucionalização de ideias e modelos construídos a partir das obras e ações de Paulo Freire. Esse movimento, segundo o autor, levou à construção de um método/sistema, à dicionarização e uma disciplinarização dos pensamentos freireanos, que podem culminar no enfraquecimento da própria crítica, tão cara para Freire e tão necessária ao processo de ensino. Essa normatização e a lógica de formatação do pensamento freireano potencializam uma redução de suas possibilidades e abrangência, uma vez que pode "[...] retirar dele o saber marginal, não oficial" (BRAYNER, 2017, p. 863).

Por outro lado, embora consideremos que a presença das discussões CTS em currículos e práticas das Escolas do Campo possa ser de grande relevância ao fortalecimento da educação que ali se realiza, poucas são as pesquisas que discutem, conjuntamente, Educação do Campo e CTS.

Contudo, mesmo considerando brevemente os temas pesquisados e os principais pontos levantados pelos autores, cabe destacar que as pesquisas apontam para o quão a Educação do Campo, as ideias de Paulo Freire e os pressupostos da Educação CTS se envolvem com a dinâmica da sociedade, problematizando a realidade existente e potencializando o olhar crítico das pessoas.

Com relação às questões curriculares, há de se destacar dois pontos muito importantes. Primeiro, a necessidade de se trabalhar o alargamento das compreensões que os professores têm quanto às concepções de currículo, para que possam, quem sabe, percebê-lo como resultado de disputas de poder, discursos dominantes, interesses e visões de mundo, indo muito além dos debates mais imediatos do contexto escolar e da definição de estratégias, conteúdos e atividades.

Disso emerge o segundo ponto a ser considerado, indicando a necessidade e a importância que os profissionais diretamente ligados à educação - professores, diretores, pedagogos - queiram e lutem por uma participação mais efetiva na elaboração de planos e currículos, constituindo um esforço de trabalho que agregue opiniões, sugestões e expectativas da comunidade. Tais ações poderão, pelo menos em parte, contemplar as necessidades e os interesses emergentes a partir da própria realidade em que a escola se situa e aproximar a educação da vida dos educandos, tornando-a mais significativa e dialógica.

\section{Referências}

APPLE, M. W. A política do conhecimento oficial: faz sentido a ideia de um currículo nacional? In: MOREIRA, A. F.; SILVA, T. T. (org.). Currículo, cultura e sociedade. 12. ed. São Paulo: Cortez, 2013. 
AULER, D. Enfoque ciência-tecnologia-sociedade: pressupostos para o contexto brasileiro. Ciência \& Ensino, Brasil, v. 1, n. esp., p. 1-20, 2007.

AULER, D. Novos caminhos para a educação CTS: ampliando a participação. In: SANTOS, W. L. P, AULER, D. (org.). CTS e educação científica: desafios, tendências e resultados de pesquisas. Brasília: Editora Universidade de Brasília, 2011. p. 73-97.

AULER, D.; BAZZO, W. A. Reflexões para a implementação do movimento CTS no contexto educacional brasileiro. Ciência \& Educação, Bauru, v. 7, n. 1, p. 1-13, 2001. DOI: https://doi. org/10.1590/S1516-73132001000100001.

AULER, D.; DELIZOICOV, D. Ciência-tecnologia-sociedade: relações estabelecidas por professores de ciências. Revista Eletrônica de Enseñanza de las Ciências, Vigo, v. 5, n. 2, p. 337-355, 2006. Disponível em: http://reec.uvigo.es/volumenes/volumen5/ART8_Vol5_N2.pdf. Acesso em: 22 mar. 2021.

AULER, D.; DALMOLIN, A. M. T.; FENALTI, V. S. Abordagem temática: natureza dos temas em Freire e no enfoque CTS. Alexandria: revista de educação em ciência e tecnologia, Florianópolis, v. 2, n. 1, p. 67-84, 2009. Disponível em: https://periodicos.ufsc.br/index.php/alexandria/article/ view/37915. Acesso em: 22 mar. 2021.

BAZZO, W. A.; VON LINSINGEN, I.; PEREIRA, L. T. V. (ed.). Introdução aos estudos CTS (ciência, tecnologia e sociedade). Madri: OEI, 2003.

BECK, U. Sociedade de risco: rumo a uma outra modernidade. 2. ed. São Paulo: Editora 34, 2011.

BRAYNER, F. H. A. "Paulofreireanismo": instituindo uma teologia laica? Revista Brasileira de Educação, Rio de Janeiro, v. 22, n. 70, p. 851-872, 2017. DOI: https://doi.org/10.1590/s141324782017227042.

CALDART, R. S. Escola do campo em movimento. In: ARROYO, M. G.; CALDART, R. S.; MOLINA, M. C. (org.). Por uma educação do campo. 5. ed. Petrópolis: Vozes, 2011. p. 87-131.

COSTA, L. M. C.; BATISTA, M. S. X. Formação continuada de educadores: uma contribuição ao currículo das escolas do campo. Revista Espaço do Currículo, João Pessoa, v. 12, n. 1, p. 25-38, 2019.

FREIRE, P. Extensão ou comunicação. 18. ed. Rio de Janeiro: Paz e Terra, 2017.

FREIRE, P. Pedagogia da autonomia: saberes necessários à prática educativa. 31. ed. São Paulo: Paz e Terra, 1996.

FREIRE, P. Pedagogia do oprimido. 67. ed. Rio de Janeiro: Paz e Terra, 2019.

GONÇALVES M. M. Diálogo freireano e formação permanente: reflexões sobre a formação de professores na educação do campo. 2018. 195 f. Dissertação (Mestrado em Educação Científica e Tecnológica) - Universidade Federal de Santa Catarina, Florianópolis, 2018.

MARQUES, L. I. B. Educação ciência-tecnologia-sociedade (CTS): elementos em produções científicas na Fundação Oswaldo Cruz - Fiocruz. 2016. 107 f. Dissertação (Mestrado em Educação) - Faculdade de Educação, Universidade de Brasília, Brasília, DF, 2016.

MOLINA, M. C.; NADAL, P. Entrevista com Mônica Molina, especialista em educação do campo. Nova Escola, São Paulo, ed. 258, dez. 2012.

PERNAMBUCO, M. M. C. A. Prefácio. In: MOLINA, M. C. (Org.). Licenciaturas em educação do campo e o ensino de ciências naturais: desafios à promoção do trabalho docente interdisciplinar. Brasília: MDA, 2014. p. 7-9.

PIMENTEL, F. A S. Qualidade de ensino: aprendizagem nas salas multisseriadas na educação do campo capixaba. 2014. 293 f. Dissertação (mestrado em Educação, Arte e História da Cultura) Universidade Presbiteriana Mackenzie, São Paulo, 2014. 
PINTO, A. V. Consciência e realidade nacional. Rio de Janeiro: Instituto Superior de Estudos Brasileiros, 1960.

ROSO, C. C.; SANTOS. R. A.; ROSA, R. E.; AULER, D. Currículo temático fundamentado em FreireCTS: engajamento de professores de física em formação inicial. Ensaio, Belo Horizonte, v. 17, n. 2, p. 372-389, 2015. DOI: https://doi.org/10.1590/1983-21172015170205.

SANTOS, C. F.; FERREIRA, C. E. Currículo e educação do campo: entre as lutas por uma formação humana crítica e as proposições pós-críticas do educar. Revista Espaço do Currículo, João Pessoa, v. 11, n. 2, p. 199-210, 2018.

SANTOS, R. A.; AULER, D. Práticas educativas CTS: busca de uma participação social para além da avaliação de impactos da ciência-tecnologia na sociedade. Ciência \& Educação, Bauru, v. 25, n. 2, p. 485-503, 2019. DOI: https://doi.org/10.1590/1516-731320190020013.

SANTOS, W. L. P.; MORTIMER, E. F. Uma análise dos pressupostos teóricos da abordagem C-T-S (ciência-tecnologia-sociedade) no contexto da educação brasileira. Ensaio, Belo Horizonte, v. 2, n. 2, p. 110-132, 2000.

SAUL, A. M.; SILVA, A. F. G. O pensamento de Paulo Freire como referência para o desenvolvimento de políticas de currículo. In: SIMPÓSIO BRASILEIRO DE POLÍTICA PÚBLICA E ADMINISTRAÇÃO DA EDUCAÇÃO, 25. e CONGRESSO IBERO-AMERICANO DE POLÍTICA E ADMINISTRAÇẨO DA EDUCAÇẨO, 2., 2011, São Paulo. Anais [...]. São Paulo: ANPAE, 2011. p. 1-13.

SILVA, K. A. L. Saberes e perspectivas dos docentes em torno do currículo de uma escola pública rural do RN. 2012. 186 f. Dissertação (Mestrado em Educação) - Universidade Federal do Rio Grande do Norte, Natal, 2012.

SILVA, M. J. A. R. Conceitos de ciências para educação do campo a partir do tema agriculturas. 2014. 121 f. Dissertação (Mestrado em Ensino de Ciências) - Universidade de Brasília, Brasília, DF, 2014.

SILVA FILHO, L. G S. Educação do campo e pedagogia Paulo Freire na atualidade: um olhar sobre o currículo do curso pedagogia da Terra da UFRN. 2014. 102 f. Dissertação (Mestrado em Educação) - Universidade Federal da Paraíba, João Pessoa, 2014.

STRIEDER, R. B. Abordagens CTS na educação científica no Brasil: sentidos e perspectivas. 2012. 142 f. Tese (Doutorado em Ciências) - Universidade de São Paulo, São Paulo, 2012. DOI: https://doi. org/10.11606/T.81.2012.tde-13062012-112417. 